\title{
Produção de repolho sob influência de boro
}

\author{
Adriana Ursulino ALVES ${ }^{1}$, José Gil dos ANJOS NETO ${ }^{1}$, Edson de Almeida CARDOSO², \\ Maristela Caetano GOMES ${ }^{1}$
}

\author{
${ }^{1}$ Departamento de Engenharias, Universidade Federal do Piauí, Bom Jesus, PI, Brasil. \\ ${ }^{2}$ Centro de Ciências Agrárias, Universidade Federal da Paraíba, Areia, PB, Brasil. \\ *E-mail: adrianaursulino35@gmail.com
}

(Orcid: 0000-0002-3074-6079; 0000-0001-8440-5280; 0000-0002-9343-7425; 0000-0002-1958-6449)

\begin{abstract}
Recebido em 24/09/2019; Aceito em 05/03/2021; Publicado em 23/04/2021.
RESUMO: As brássicas possuem alta exigência em boro. O suprimento inadequado deste micronutriente pode limitar a sua produção, principalmente devido à baixa disponibilidade do elemento em determinados tipos de solos. Isso porque este elemento contribui na incorporação de cálcio na parede celular e diretamente no processo de expansão celular, tendo atuação também direta no crescimento e desenvolvimento dessas hortaliças. Assim, objetivou-se nesse trabalho, avaliar a produção de repolho em condições semiáridas no Sul do Piauí, utilizando diferentes doses de ácido bórico. O experimento foi conduzido no Setor de Horticultura do Campus Professora Cinobelina Elvas, da Universidade Federal do Piauí, no Município de Bom Jesus - PI no período de fevereiro a junho de 2012. O delineamento experimental utilizado foi em blocos casualizados, cujos tratamentos foram compostos por cinco doses de boro $\left(0,2,4,6\right.$ e $\left.8 \mathrm{~kg} \mathrm{ha}^{-1}\right)$ e quatro repetições. Foram avaliadas as seguintes variáveis: altura de planta, circunferência da cabeça, área foliar, massa média da cabeça, produtividade, concentração de boro no solo e teores de boro na cabeça e folhas. As doses de boro aplicadas foram significativas para a circunferência da cabeça, massa média da cabeça, teor de boro nas folhas e produtividade. E não apresentaram efeito significativos nas variáveis altura da planta, área foliar, concentração de boro no solo e teor de boro na cabeça. Para incrementar a qualidade das cabeças é necessário uma maior demanda de boro, pois foi obtido máximos valores para circunferência da cabeça $(54,65 \mathrm{~cm})$ e da massa média da cabeça $(1,41 \mathrm{~kg})$ com a aplicação de 4,39 e 4,35 $\mathrm{kg} \mathrm{ha}^{-1}$ de boro. Enquanto a produtividade máxima de 68, $56 \mathrm{t} \mathrm{ha}^{-1}$ de repolho foi obtida com $3,89 \mathrm{~kg} \mathrm{ha}^{-1}$ de boro. Nas condições semiáridas do Sul do Piauí, a produtividade e a qualidade do repolho, é alcançada com aplicação de 4,0 a 4,5 $\mathrm{kg} \mathrm{ha}^{-1}$ de boro no solo.
\end{abstract}

Palavras-chave: Brassica oleracea var. capitata; ácido bórico; nutrição mineral; rendimento.

\section{Production of cabbage under the influence of boron}

\begin{abstract}
Brassica has a high demand for boron. The inadequate supply of this micronutrient can limit its production, mainly due to the low availability of the element in certain types of soils. This is because this element contributes to the incorporation of calcium in the cell wall and directly in the cell expansion process, having a direct role in the growth and development of these vegetables. Thus, the objective of this work was to evaluate the production of cabbage in semi-arid conditions in southern Piauí, using different doses of boric acid. The experiment was carried out in the Horticulture Sector of the Professora Cinobelina Elvas Campus, at the Federal University of Piauí, in the municipality of Bom Jesus - PI from February to June 2012. The experimental design used was in randomized blocks, whose treatments were composed by five doses of boron $\left(0,2,4,6\right.$ and $\left.8 \mathrm{~kg} \mathrm{ha}^{-1}\right)$ and four repetitions. The following variables were evaluated: plant height, head circumference, leaf area, average head mass, productivity, boron concentration in the soil and boron levels in the head and leaves. The applied boron doses were significant for the head circumference, average head mass, boron content in the leaves and productivity. And they have no significant effect on the variables plant height, leaf area, boron concentration in the soil and boron content on the head. To increase the quality of the heads, a greater demand for boron is necessary, as maximum values for head circumference $(54.65 \mathrm{~cm})$ and average head mass $(1.41 \mathrm{~kg})$ were obtained with the application of 4.39 and $4.35 \mathrm{~kg} \mathrm{ha}^{-1}$ of boron. While the maximum productivity of $68.56 \mathrm{t} \mathrm{ha}^{-1}$ of cabbage was obtained with $3.89 \mathrm{~kg} \mathrm{ha}^{-1}$ of boron. In the semi-arid conditions of southern Piauí, the productivity and quality of the cabbage is achieved with the application of 4.0 to $4.5 \mathrm{~kg}$ ha${ }^{1}$ of boron in the soil.

Keywords: Brassica oleracea var. capitata; boric acid; mineral nutrition; yield.
\end{abstract}

\section{INTRODUÇÃO}

As Brássicas, especialmente o repolho, devido à facilidade de produção e conservação pós-colheita tem contribuído muito com a segurança alimentar do ser humano ao longo dos séculos. No Brasil, o repolho é a espécie de maior importância no grupo das brássicas. Sua produção está concentrada nas regiões Sul e Sudeste, com produtividade média de 40 t ha-1 (FONTES; NICK, 2019).

A adubação constitui uma das práticas agrícolas mais caras e de maior retorno econômico, resultando em maiores 
rendimentos e em produtos mais uniformes e de maior valor comercial (PRIMAVESI, 2002; SEDIYAMA et al, 2009). O boro é o micronutriente que mais limita a produção das culturas, desempenhando diversas funções nas plantas, como a formação da parede celular, a divisão celular e o aumento no tamanho das células (MALAVOLTA, 2006), o que o torna de grande importância para a produção de hortaliças.

A deficiência em boro afeta os pontos de crescimento das plantas, diminuindo consequentemente a qualidade do produto e reduzindo a produção. Esta também provoca o rápido endurecimento da parede celular, porque mesmo formando complexos com carboidratos, a disposição das micelas de celulose fica prejudicada, impedindo o aumento normal do volume da célula (MALAVOLTA, 1980).

A deficiência de boro em repolho provoca problemas nutricionais, como o aparecimento de talos ocos, coloração escura na parte central do caule, produção de cabeças pequenas e pouco compactas. Essa deficiência nutricional provoca perdas tanto na qualidade como na produtividade dessa hortaliça, ocasionando-se prejuízos econômicos (FILGUEIRA, 2008).

O repolho originalmente é uma hortaliça de clima temperado e a temperatura é o fator que mais limita o desenvolvimento da planta (SILVA JÚNIOR, 1987; FILGUEIRA, 2008). No entanto, devido a disponibilidade de cultivares adaptadas a temperaturas elevadas, ampliou-se os períodos de plantio e de colheita. Deste modo, pela escolha criteriosa da cultivar, a época de plantio é possível a sua produção ao longo do ano (FILGUEIRA, 2008).

A Região Sul do Piauí apresenta condições semiáridas e a produção de hortaliças é bastante limitada. Esta é realizada principalmente por produtores familiares e limita-se as hortaliças de manejo mais simples como alface, coentro, cebolinha e couve. Mediante esta realidade, viu-se a necessidade de fazer pesquisas com outras culturas olerícolas.

Em virtude de o repolho ser uma brássica de alto valor econômico e alta aceitação pelos consumidores, foi visto a possibilidade de a cultura se adaptar as condições da região e abrir portas para a produção de novas hortaliças. Assim, dando outras opções aos produtores da região, bem como, despertar o interesse de outros produtores a desenvolver a produção de Hortaliças nesta região. Diante do exposto, as hipóteses desse trabalho são: 1) a cultura se adaptará as condições climáticas da região; 2) as doses de boro serão suficientes para atingir ou superar a produtividade média de $40 \mathrm{t} \mathrm{ha}^{-1}$; 3) o boro aplicado garantirá qualidade aos repolhos produzidos; 4) haverá uma dose ou doses a serem recomendadas para a produção de repolho em condições semiáridas no Sul do Piauí. Assim, objetivou-se nesse trabalho, avaliar a produção de repolho em condições semiáridas no Sul do Piauí, utilizando diferentes doses de ácido bórico.

\section{MATERIAL E MÉTODOS}

O experimento foi conduzido em campo aberto, no período de fevereiro a junho de 2012, no Setor de Horticultura do Campus Professora Cinobelina Elvas, da Universidade Federal do Piauí. O município integra a região do Semiárido Piauiense, possuindo clima quente e úmido, classificado por Köppen como Awa (Tropical chuvoso com estação seca no inverno e temperatura média do mês mais quente superior a $22{ }^{\circ} \mathrm{C}$ ). Localizado nas coordenadas geográficas $09^{\circ} 04$ '28' S, 4421'31'” W, e altitude média de 277 $\mathrm{m}$, com precipitação média entre 900 a $1200 \mathrm{~mm} \mathrm{ano}^{-1} \mathrm{e}$ temperatura média de $26,2^{\circ} \mathrm{C}$ (INMET, 2021).

O solo da área é classificado como Latossolo Amarelo (EMBRAPA, 2018), antes da realização do experimento foi extraída amostras do solo na camada de 0,0 a $0,20 \mathrm{~m}$ para caracterização química sendo os resultados apresentados na Tabela 1.

O delineamento experimental adotado foi o de blocos casualizados, com cinco tratamentos e quatro repetições. Os tratamentos foram compostos por cinco doses de boro $(0,2$, 4,6 e $\left.8 \mathrm{~kg} \mathrm{ha}^{-1}\right)$. Cuja fonte utilizada foi o ácido bórico com $17 \%$ de B. As doses foram aplicadas oito dias antes do transplante. As quantidades de boro, de cada tratamento e repetição foram diluídas em dois litros de água fervente $\mathrm{e}$ acondicionadas em garrafas pet. As soluções foram colocadas em regador manual e acrescentaram-se três litros de água para completar a capacidade máxima do regador e foram aplicadas aos canteiros, sendo utilizado um regador para cada dose para evitar contaminação e comprometimento da pesquisa.

Tabela 1. Caracterização do Latossolo Amarelo, Bom Jesus-PI. Table 1. Characterization of the Yellow Latosol, Bom Jesus-PI.

\begin{tabular}{lc}
\hline Atributos* & Latossolo Amarelo \\
\hline $\mathrm{pH}$ em CaCl & \\
$\mathrm{P}$ resina $\left(\mathrm{mg} \mathrm{dm}^{-3}\right)$ & 5,9 \\
$\mathrm{~K}\left(\mathrm{cmolc} \mathrm{dm}^{-3}\right)$ & 11 \\
$\mathrm{Ca}\left(\mathrm{cmolc} \mathrm{dm}^{-3}\right)$ & 2,8 \\
$\mathrm{Mg}\left(\mathrm{cmolc} \mathrm{dm}^{-3}\right)$ & 75 \\
$\mathrm{H}+\mathrm{Al}\left(\mathrm{cmolc} \mathrm{dm}^{-3}\right)$ & 15 \\
$\mathrm{~B}\left(\mathrm{mg} \mathrm{dm}^{-3}\right)$ & 18 \\
Soma de Bases $\left(\mathrm{cmolc} \mathrm{dm}^{-3}\right)$ & 0,21 \\
$\mathrm{CTC}\left(\mathrm{cmolc} \mathrm{dm}^{-3}\right)$ & 92,8 \\
Saturação por Bases $(\%)$ & 110,8 \\
Matéria Orgânica $\left(\mathrm{g} \mathrm{dm}^{-3}\right)$ & 83 \\
\hline
\end{tabular}

*Todos os atributos foram analisados conforme a metodologia do Boletim Técnico do IAC, $n^{\circ} 106$ (CAMARGO et al., 2009), com exceção do Boro, que se utilizou o método da azometina (TEDESCO, 1995); *All attributes were analyzed according to the methodology of the Technical Bulletin of the IAC, No. 106 (CAMARGO et al., 2009), with the exception of Boron, which used the azomethine method (TEDESCO, 1995).

A correção do solo não foi necessária, uma vez que a Saturação por Bases se encontrava em $83 \%$. O preparo do solo foi por meio de aração e gradagem. O levantamento dos canteiros realizado manualmente a uma altura de $0,30 \mathrm{~m}$, cuja as dimensões de cada parcela foi de 3,10 x 2,50 m, com uma área total de $7,75 \mathrm{~m}^{2}$. Sendo quatro linhas de cinco plantas por canteiro espaçadas de $0,80 \times 0,50 \mathrm{~m}$, e considerou-se como área útil da parcela as seis plantas das linhas centrais, sendo excluídas uma planta de cada extremidade que formaram a bordadura.

A adubação e a semeadura ocorreram de forma manual. A semeadura foi realizada em bandejas de polipropileno de 128 células com o híbrido Astrus Plus, as quais foram preenchidas com substrato comercial Bioplant ${ }^{\circledR}$ e as mudas transplantas para os canteiros aos 34 dias após a semeadura (DAS), quando estavam com quatro folhas definitivas. $\mathrm{Na}$ adubação de plantio aplicou-se em todos os tratamentos como fonte de potássio o $\mathrm{KCl}\left(60 \%\right.$ de $\left.\mathrm{K}_{2} \mathrm{O}\right)$, na dose de $100 \mathrm{~kg} \mathrm{ha} \mathrm{k}^{-1}$ e como fonte de fósforo o superfosfato simples (18\% de $\left.\mathrm{P}_{2} \mathrm{O}_{5}\right)$, na dose de $240 \mathrm{~kg} \mathrm{ha}^{-1}$. Aos 15, 30 e 45 dias após o transplante (DAT) foram realizadas as adubações de cobertura com ureia $(45 \%$ de $\mathrm{N})$ na dose de $300 \mathrm{~kg} \mathrm{ha}^{-1}$ de $\mathrm{N}$ e com cloreto de potássio na dose de $220 \mathrm{~kg} \mathrm{ha}^{-1}$ (UNIVERSIDADE FEDERAL DO CEARÁ, 1993). 
As irrigações foram efetuadas por microaspersão com fitas perfuradas, com turno de rega diário parcelado em duas aplicações (manhã e tarde), trabalhando com vazão de 1,7 Lh1. O monitoramento e o controle de plantas daninhas, insetos pragas e doenças foram feitos semanalmente. Para as plantas daninhas o controle foi através da capina manual periodicamente até o fim do experimento. As pragas encontradas foram à Traça das brássicas (Plutella xylostella) e pulgão da couve (Brevicoryne brassicae). Sendo feito o controle com pulverizações com o inseticida malatol ${ }^{\circledR} 500 \mathrm{CE}$ na dosagem de $1,5 \mathrm{~mL}$ do produto comercial para um litro de água quando da ocorrência das pragas.

As avaliações ocorreram na fase de colheita. Esta foi realizada aos 90 dias após o transplante quando mais de $80 \%$ das plantas da parcela estavam com a cabeça compacta e com a borda da folha externa iniciando seu desprendimento da cabeça do repolho. Sendo avaliadas as seguintes variáveis:

Variáveis Fitotécnicas: altura da planta e circunferência da cabeça, com o auxílio de uma fita métrica, sendo determinada a partir da zona do colo até o ápice da planta e em volta da cabeça, respectivamente, expresso em $\mathrm{cm}$; área foliar: foi determinada com o medidor de área foliar da marca LICOR, modelo LI 3000, expresso em $\mathrm{cm}^{2}$ planta $^{-1}$; massa média da cabeça e produtividade: determinadas pelo peso médio da cabeça e soma da massa da cabeça, em balança digital da marca Filizola $^{\circledR}$ com capacidade máxima de $5 \mathrm{~kg}$, respectivamente, sendo os valores expresso em $\mathrm{kg}$ e $\mathrm{t} \mathrm{ha}{ }^{-1}$.

Variáveis Nutricionais: A concentração de boro no solo e teores de boro na cabeça e folhas foram determinadas de acordo com metodologia proposta por Tedesco (1995). Para o boro no solo após a colheita foram coletadas amostras em cada parcela experimental, secas a temperatura ambiente e acondicionadas em sacos de papel Kraft, enquanto que o material vegetal (cabeça e folhas) foram lavados em água corrente e água destilada e acondicionadas em sacos de papel Kraft, sendo estes secos em estufa com circulação forçada de ar a $65^{\circ} \mathrm{C}$. Após o período de secagem o material vegetal foi moído e juntamente com as amostras de solo enviados ao Laboratório de Análise de Solo e Planta da Universidade Estadual Paulista, Campus de Jaboticabal, para análises.

Os dados foram submetidos à análise de variância, pelo teste " $F$ ", com um nível de significância de 0,05 e aquelas variáveis que apresentaram efeito significativo foram submetidas à análise quantitativa de regressão polinomial, sendo escolhido o modelo com maior coeficiente de determinação.

\section{RESULTADOS}

Houve efeito significativo da aplicação de boro nas seguintes variáveis: circunferência da cabeça, massa média da cabeça, teor de boro nas folhas e produtividade. A altura da planta, área foliar, concentração de boro no solo e teor de boro na cabeça não foram influenciados significativamente pelas doses de boro aplicadas no solo, sendo seus valores médios de 27,71 cm; 8166,84 $\mathrm{cm}^{2} ; 0,26 \mathrm{mg} \mathrm{dm}^{-3}$ e 36,75 mg $\mathrm{kg}^{-1}$, respectivamente.

A resposta do teor de boro nas folhas de repolho a diferentes doses de boro pode ser observada na Figura 1. A variação nos teores de boro nas folhas de repolho foi de 27 (controle) a $49 \mathrm{mg} \mathrm{kg}^{-1}$ (dose máxima estimada de $6 \mathrm{~kg} \mathrm{ha}^{-1}$ ), estando dentro da faixa adequada indicada por Trani e Raij (1996) que é de 25 a $75 \mathrm{mg} \mathrm{kg}^{-1}$. E com a dose máxima aplicada de $8 \mathrm{~kg} \mathrm{ha}^{-1}$, há uma redução de $4 \%$ no teor de boro nas folhas.

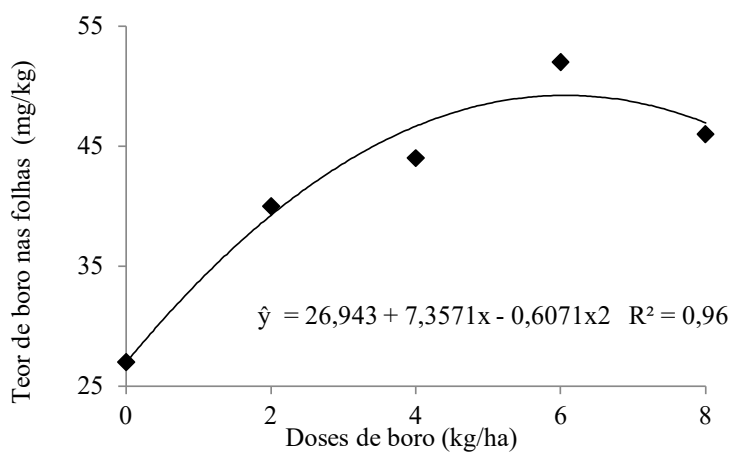

Figura 1. Teor de boro nas folhas de repolho em diferentes doses de boro.

Figure 1. Boron content in cabbage leaves at different doses of boron.

A resposta da qualidade de cabeças de repolho a diferentes doses de boro pode ser observada nas Figuras 2 e 3. Nota-se que à medida que se aumentaram as doses de boro, até próximo a 4,5 $\mathrm{kg} \mathrm{ha-1}$, houve um aumento da circunferência e da massa média da cabeça. Observa-se que os máximos valores para circunferência da cabeça $(54,65 \mathrm{~cm})$ e da massa média da cabeça $(1,41 \mathrm{~kg})$ foram atingidos com a aplicação de 4,39 e $4,35 \mathrm{~kg} \mathrm{ha}^{-1}$ de boro, respectivamente. Sendo constatado incrementos de 10,45 e $28,92 \%$ sobre a circunferência e massa média da cabeça em relação a dose zero (controle) e as doses máximas estimadas. Contudo, observou-se redução de 6,40 e 16,25 \% nessas variáveis com aplicação de $8 \mathrm{~kg} \mathrm{ha}{ }^{-1}$ de boro (dose máxima aplicada).

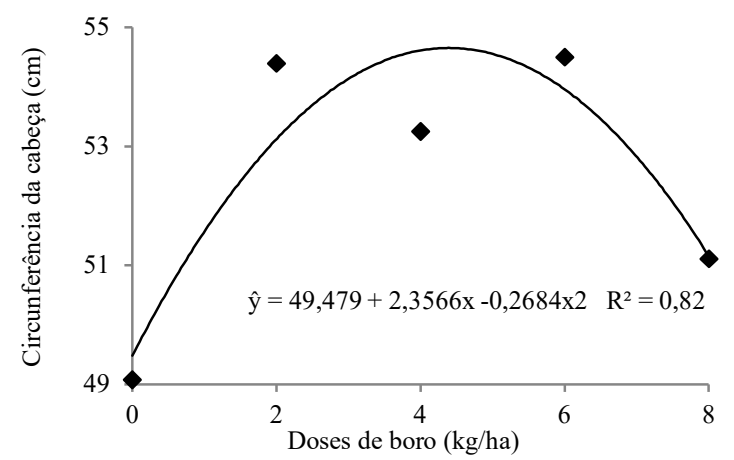

Figura 2. Circunferência da cabeça de repolho em diferentes doses de boro.

Figure 2. Circumference of cabbage head in different doses of boron.



Figura 3. Massa média da cabeça de repolho em diferentes doses de boro.

Figure 3. Average mass of cabbage head in different doses of boron. 
Os dados referentes à produtividade são apresentados na Figura 4. Pode-se observar que a produtividade máxima de repolho $\left(68,56 \mathrm{t} \mathrm{ha}^{-1}\right)$ foi obtida com a dose de 3,89 $\mathrm{kg} \mathrm{ha}^{-1}$ boro. Em relação ao tratamento controle $\left(0,0 \mathrm{~kg} \mathrm{ha}^{-1}\right.$ boro $)$ houve um incremento de 33\% (17 $\left.\mathrm{t} \mathrm{ha}^{-1}\right)$ na produtividade com aplicação de 3,89 (dose máxima estimada) $\mathrm{kg} \mathrm{ha}^{-1}$ de boro. E utilizando-se a dose máxima aplicada de $8 \mathrm{~kg} \mathrm{ha}^{-1}$ ocorreria uma redução de $27 \%\left(18,8 \mathrm{t} \mathrm{ha}^{-1}\right)$ na produtividade de cabeças.

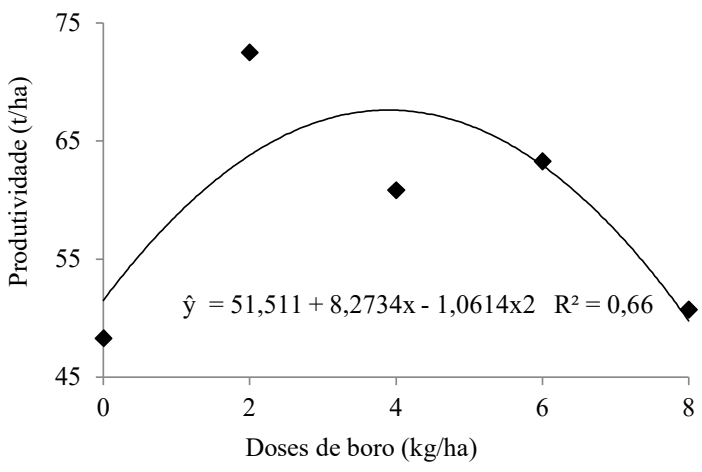

Figura 1. Produtividade de repolho em diferentes doses de boro. Figure 4. Productivity of cabbage in different doses of boron.

\section{DISCUSSÃO}

O teor de boro foliar em virtude da aplicação de boro no solo é muito variável na cultura do repolho. Esta prerrogativa foi constatada por vários autores, como: Silva et al. (2012), com as cultivares 'Chato de Quintal' e '60 Dias', cuja variação foi de 33 a $81 \mathrm{mg} \mathrm{kg}^{-1}$, ao aplicarem 0 a $10 \mathrm{~kg} \mathrm{ha}^{-1}$ de boro, respectivamente; Silva et al. 2014, com a cultivar Astrus Plus obtiveram teor foliar máximo de $49 \mathrm{mg} \mathrm{kg}^{-1}$; Pizetta et al. (2005), com híbrido Kenzan observaram teor foliar entre 33 a $81 \mathrm{mg} \mathrm{kg}^{-1}$; Bergamin et al., 2005 também com o híbrido Kenzan obteve teor boro foliar variando de 23 a $44 \mathrm{mg} \mathrm{kg}^{-1}$; e Trani; Raij (1996), afirmaram que o teor de boro foliar devem estar situados na faixa de 25-75 $\mathrm{mg} \mathrm{kg}^{-1}$ ).

A adequação dos valores do teor de boro nas folhas quando submetidas a todas as doses demonstra que a cultura do repolho, mesmo em teores acima do que é indicado, suporta uma larga faixa de boro foliar sem demonstrar sintomas visíveis de toxicidade. Isso porque o máximo teor (49 $\mathrm{mg} \mathrm{kg}^{-1}$ ) foi obtido com a dose de $6 \mathrm{~kg} \mathrm{ha}^{-1}$ e Silva et al. (2014) com o híbrido Astrus aplicando $10 \mathrm{~kg} \mathrm{ha}^{-1}$ de boro ao solo obtendo-se teor foliar de $49 \mathrm{mg} \mathrm{kg}^{-1}$ também não verificaram sintomas visíveis de toxicidade nas folhas. Contudo, Trani et al. (1996) recomendam para o estado de São Paulo 3 a $4 \mathrm{~kg} \mathrm{ha}^{-1}$ de B para brócolis, couve-flor e repolho, sem levar em consideração as características do solo, ou três aplicações foliares durante o ciclo com solução contendo $1 \mathrm{~g} \mathrm{~L}^{-1}$ de ácido bórico.

A redução observada na circunferência e massa média da cabeça em doses acima de $4 \mathrm{~kg} \mathrm{ha}{ }^{-1}$ de boro indica que níveis excessivos de boro provocam redução na qualidade de cabeças de repolho. Contudo, as reduções não foram tão expressivas, com percentuais de 6 e $16 \%$ na circunferência e massa média da cabeça. A massa média da cabeça atingiu 1,4 $\mathrm{kg} \operatorname{com} 4,35 \mathrm{~kg} \mathrm{ha}^{-1}$ de boro aos 90 dias após o transplante. Demonstrando boa adaptação as condições semiáridas do Sul Piauiense, isso porque de acordo com Luz et al. (2002) o híbrido Astrus produz cabeças com peso entre 1,5 e 2,0 kg, ciclo variando entre 80 a 90 dias), além de ser tolerante ao calor.

A produtividade de repolho é bastante variável. No presente trabalho atingiu-se 68,56 $\mathrm{t} \mathrm{ha}^{-1}$ com a dose de 3,89 $\mathrm{kg} \mathrm{ha}{ }^{-1}$; Bergamin et al. (2005) obtiveram produtividade máxima de $65,95 \mathrm{t} \mathrm{ha}^{-1}$ ao utilizarem $8 \mathrm{~kg} \mathrm{ha}^{-1}$ de 'boro'; Silva et al. (2012) com 28,8 t ha-1 aplicando 7,2 $\mathrm{kg} \mathrm{ha}^{-1}$ de boro; Silva et al. (2014) obtiveram 31,2 $\mathrm{t} \mathrm{ha}^{-1}$ com a dose de $6,8 \mathrm{~kg}$ ha $^{-1}$ de 'boro'.

O resultado de produtividade obtido neste experimento está acima da faixa citada por Trani e Raij (1996), que é de 30 a 60 t ha $^{-1}$. Esta diferença de comportamento, em parte, devese a cultivares mais produtivas desenvolvidas nos últimos anos. Além de melhorias na adubação e nutrição das plantas que são adotados pelos produtores. Pizetta et al. (2005), em trabalhos com brócolis, repolho e couve-flor obteve respostas positivas com o aumento das doses de $\mathrm{B}$ nas culturas. Demonstrando assim, a forte relação existente da aplicação de B com o aumento da produtividade na cultura das brássicas.

$\mathrm{O}$ incremento máximo na produtividade do híbrido Astrus, em relação à testemunha $\left(0,21 \mathrm{mg} \mathrm{dm}^{-3}\right.$ de boro no solo), de $33 \%$ com a dose 3,89 kg.ha- ${ }^{-1}$ superou os de Pizetta et al. (2005) que apresentaram, em relação à testemunha $(0,15 \mathrm{mg}$ $\mathrm{dm}^{-3}$ de boro no solo) um incremento de $13 \%$ na produtividade do híbrido Kenzan com aplicação de $8 \mathrm{~kg} \mathrm{ha}^{-1}$ de boro.

\section{CONCLUSÕES}

Nas condições semiáridas do Sul do Piauí, a produtividade e a qualidade do repolho, é alcançada com aplicação de 4,0 a 4,5 $\mathrm{kg} \mathrm{ha}^{-1}$ de boro no solo.

\section{AGRADECIMENTOS}

Os autores agradecem a Universidade Federal do Piauí (UFPI), Campus Universitário Professora Cinobelina Elvas (CPCE) pelo apoio técnico e de infraestrutura e ao Conselho Nacional de Desenvolvimento Científico e Tecnológico (CNPq) pelo auxílio financeiro (bolsa) a pesquisa desenvolvida.

\section{REFERÊNCIAS}

AQUINO, B. F.; HERNANDEZ, F. F. F.; HOLANDA, F. J. M.; FREIRE, J. M.; CRISÓSTOMO, L. A.; COSTA, R. I.; UCHÔA, S. C. P.; FERNANDES, V. L. B. Recomendações de adubação e calagem para o estado do Ceará. 1 ed. Fortaleza: UFC, 1993. 247p.

BERGAMIN, L. G.; CRUZ, M. C. P.; FERREIRA, M. E.; BARBOSA, J. C. Produção de repolho em função da aplicação de boro associada a adubo orgânico. Horticultura Brasileira, v. 23, n. 2, p. 311-315, 2005. http://dx.doi.org/10.1590/S010205362005000200030

CAMARGO, O. A.; MONIZ, A. C.; JORGE, J. A.; VALADARES, J. M. A. S. Métodos de Análise Química, Mineralógica e Física de Solos do Instituto Agronômico de Campinas. Campinas: Instituto Agronômico/ Fundação IAC, 2009. 77p. (Boletim Técnico, 106, Edição revista e atualizada).

EMBRAPA. Empresa Brasileira de Pesquisa Agropecuária. Sistema brasileiro de classificação de solos. 5 ed. Rio de Janeiro: Embrapa Solos, 2018. 356p.

FILGUEIRA, F. A. R. Novo Manual de Olericultura: agrotecnologia moderna na produção $\mathrm{e}$ 
comercialização de hortaliças. Viçosa: Editora UFV, 2008. 421p.

FONTES, P. C. R.; NICK, C. Olericultura: Teoria e prática. 2 ed. Viçosa: Editora UFV/DFT, 2019. 632 p.

INMET_Instituto Nacional de Meteorologia. Normal climatológica. Disponível em: http://www.inmet.gov.br/portal/index.php?r=clima/n ormaiClimatologicas. Disponível em: < http:// www.inmet.gov.br> Acesso em 11 de fevereiro de 2021.

LUZ, F. J. F.; SABOYA, R. C. C.; PEREIRA, P. R. V. S. O cultivo do repolho em Roraima. Boa Vista-RO: Embrapa Roraima, 2002. 17p.

MALAVOLTA E. Elementos de Nutrição Mineral de Plantas. São Paulo: Agronômica Ceres, 251p. 1980.

MALAVOLTA, E. Manual de nutrição mineral de plantas. São Paulo: Agronômica Ceres, v. 1. 2006. 638 p. 1980.

PIZETTA, L. C.; FERREIRA, M. E.; CRUZ, M. C. P.; BARBOSA, J. C. Resposta de brócolis, couve-flor e repolho à adubação com boro em solo arenoso. Horticultura Brasileira, v. 23, n. 1, p. 51-56, 2005. DOI: https://doi.org/10.1590/S010205362005000100011.

PRIMAVESI, A. Manejo Ecológico do Solo: a agricultura em regiões tropicais. São Paulo: Nobel, 2002. 541p.

SILVA JÚNIOR, A. A. Repolho: fitologia, fitotecnia, tecnologia alimentar e mercadológica. Florianópolis: EMOASC, 1987. 259p.

SILVA, K. S.; SANTOS, E. C. M.; BENET'T, C. G. S.; LARANJEIRA, L. T.; EBERHARDT NETO, E.; COSTA, E. Produtividade e desenvolvimento de cultivares de repolho em função de doses de boro. Horticultura Brasileira, v. 30, n. 3, p. 520-525, 2012. https://doi.org/10.1590/S010205362012000300027.

SILVA, L. M.; BASÍLIO S. A.; SILVA JÚNIOR, R. L.; NASCIMENTO, M. V.; BENETT, C. G. S.; BENETT, K. S. S. Aplicação de ácido bórico sobre as características produtivas do repolho em diferentes épocas. Revista de Agricultura Neotropical, Cassilândia, v. 1, n. 2, p. 2634, 2014. DOI: $10.32404 /$ rean.v1i2.228

SEDIYAMA, M. A. N.; VIDIGAL, S. M.; SANTOS, M. R.; SALGADO, L. T. Rendimento de pimentão em função da adubação orgânica e mineral. Horticultura Brasileira, Brasília, v. 27, n. 3, p. 294-299. 2009. DOI: 10.1590/S0102-05362009000300006

TEDESCO, M. J.; GIANELLO, C.; BISSANI, C. A.; BOHEN, H.; VOLKWEISS, S. Análise de solo, planta e outros materiais. Porto Alegre: Departamento de Solo. Faculdade de Agronomia. Universidade do Rio Grande do Sul, 1995. 174 p.

TRANI, P. E.; RAIJ, B. Hortaliças. In: RAIJ, B.; CANTARELLA, H.; QUAGGIO, J. A.; FURLANI, A. M. C. (Ed.) Recomendações de adubação e calagem para o Estado de São Paulo. Campinas: Instituto Agronômico/Fundação IAC, 1996. p. 157-164. (Boletim Técnico, 100) 